\title{
Sociedad, justicia y violencia ${ }^{1}$
}

\author{
Luis Armando González² \\ El autor cree que el camino más adecuado para responder efectivamente \\ al problema de la violencia, pasa inexorablemente por la superación de las \\ injusticias para que se pueda avanzar hacia una sociedad más integrada, más \\ estable y más solidaria.
}

The author posits that to provide an effective solution to violence, it is absolutely essential to overcome injustice in order to move forward to a more integrated and more stable society that shows solidarity.

\section{Introducción}

Las palabras "sociedad", “justicia” y "violencia” remiten a ámbitos de la realidad humana distintos, pero estrechamente relacionados. La sociedad, como realidad, es el ámbito de las relaciones entre individuos y grupos, relaciones a partir de las cuales la sociedad se integra o se desintegra. La justicia, por su parte, cobra vida en el plano normativo ético y jurídico. Tiene indudablemente correlatos económicos, sociales y culturales, pero el criterio último que la define -ajustar, dar a cada cual lo que le corresponde según la ley o según el deber ser- es ciertamente normativo. La violencia, finalmente, es una práctica social particular (o un conjunto de prácticas) que, cualificada como violencia psicológica, violencia política o violencia social (en sus diversas concreciones: cotidiana, familiar, criminal), se caracteriza por el ejercicio de la fuerza potencial o efectiva por parte de unos actores sociales en contra de otros.

La integración (social y cultural) es una condición imprescindible para la estabilidad social y, más radicalmente aún, para la sobrevivencia de la sociedad como proyecto de convivencia colectiva. La violencia, cuando se generaliza y escapa al control institucional, socava la integración social, llegando a amenazar la supervivencia de la sociedad en su conjunto. Cuando esto sucede, la exigencia fundamental de la justicia -dar a cada cual lo que le corresponde según la ley y según el deber ser- se ve socavada en sus raíces. Porque la violencia

1. Documento preparado para ser expuesto en el foro "Sociedad, justicia y violencia", organizado por la Unidad de Justicia Juvenil de la Corte Suprema de Justicia (4 de noviembre de 2010).

2. Coordinador de la Unidad de Investigación y Desarrollo Judicial, de la Dirección de Planificación Institucional (DPI) del Órgano Judicial. Al autor agradece a José Eduardo Navarro, Jefe de la Unidad de Información y Estadística de la DPI sus comentarios y observaciones al presente documento. 
está en el polo opuesto de la justicia: y así como esta última hace posible la integración de la sociedad, aquélla socava esa integración, pues las prácticas que la caracterizan son esencialmente desintegradoras de la convivencia colectiva. Por lo mismo, ahí donde hay graves injusticias no sólo puede irrumpir la violencia, sino que la integración social se vuelve una quimera.

La integración social, en este sentido, tiene una cara que mira hacia la justicia (que si existe la fortalece y si falta la erosiona) y otra que mira hacia la violencia (que es siempre una amenaza para la integración social). Asimismo, aunque la violencia es un corrosivo de la integración social, por lo general la violencia suele ser una manifestación de la desintegración social (y no su causa), siendo la injusticia un importante factor causal de la desintegración social. Gráficamente, la relación entre los tres ámbitos que nos ocupan queda así: (in)justicia (des)integración social violencia. Pero también opera, por la circularidad de algunos fenómenos sociales, una relación inversa: violencia (des)integración social (in)justicia.

Como puede verse, un asunto relevante cuando se habla de sociedad, justicia y violencia es el de la integración social. Dedicaré una reflexión inicial a esta temática, para pasar en segundo lugar al tema de la violencia, teniendo en la mira lo que sucede en El Salvador. Por último, trataré el tema de la justicia, ofreciendo algunas nociones teóricas básicas, aunque prestando atención a la relación entre justicia y violencia.

\section{A propósito de la integración social ${ }^{3}$}

Sociológicamente, la integración social tiene la primacía no sólo como objeto de reflexión teórica, sino como propósito de convivencia humana. Y ello porque una sociedad desintegrada, además inestable e insegura, es inviable en tanto que sociedad. La preocupación por la integración social -es decir, por la inclusión y el sentido de pertenencia de todos los miembros de una sociedad en un proyecto de convivencia común- está presente en las elaboraciones intelectuales que, en su carácter de filosofía social y política, nos legaron Platón y Aristóteles. Para estos dos autores, concretamente, fue inequívoca la preocupación por aportar sus conocimientos para la conquista de una sociedad estable y próspera, ajena a los desequilibrios y la anarquía.

Cuando la sociología adquiere el estatus de ciencia esta preocupación es replanteada con nuevos bríos, en un contexto histórico distinto al que vio nacer las especulaciones de los clásicos del pensamiento griego. Se trata de un contexto dominado por el capitalismo -con las exclusiones propias que este sistema económico genera-, pero con el trasfondo de una cosmovisión -que comienza a echar raíces en el Renacimiento y que posteriormente se afirma

3. Este tema ha sido abordado de manera más sistemática en L.A. González, Cultura, educación e integración social en El Salvador. Cuaderno de Trabajo No. 1. CENICSH, junio de 2010. 
en las teorías del contrato social y la Ilustración- en la cual todos los seres humanos -hombres en la terminología de la época- son iguales ante la ley y, por tanto, sujetos de derechos fundamentales (a la vida, a la propiedad, a la libertad y a la igualdad) 4 .

Así, la sociología como ciencia surge en un contexto de cambios no sólo políticos, sino también económicos, sociales y culturales. Estos cambios se articulan alrededor de la revolución industrial y la consolidación del capitalismo de libre competencia propiciado por aquélla. Estamos situados en la segunda mitad del siglo XIX, que es cuando el capitalismo está a las puertas de irrumpir en el escenario mundial en lo que Vladimir Ilich Lenin llamó su fase imperialista. La sociología se constituye en ese escenario de auge capitalista; y surge para intervenir -como potenciadora de los mismos- en esos cambios. Es decir, la sociología, en su constitución como disciplina científica, es un saber transformador, bien sea por una vía revolucionaria o bien sea por una vía reformista. La idea es transformar para mejorar; y un síntoma de la mejora social es la estabilidad.

Desde entonces hasta nuestros días, la integración va a ser entendida como la clave de la estabilidad social. Y la gran amenaza a exorcizar va a ser la desintegración social -entendida como la fractura en los mecanismos de inclusión y del sentido de pertenencia por parte de los miembros de la sociedad-, que se intentará atajar por distintos medios, no siempre eficaces y acordes con las raíces de los problemas generadores de desintegración.

Una de las tesis firmes en la sociología clásica y contemporánea es que una sociedad corre un riesgo potencial de desintegración cuando genera exclusiones -económicas, culturales $\mathrm{o} / \mathrm{y}$ políticas - que afectan a sectores significativos suyos. Marginalidad económica, pobreza, desempleo, bajos salarios, precariedad en las condiciones de vida, insuficientes servicios de salud y educación, escasas o nulas oportunidades de participación política... Estos factores, cuando involucran a sectores amplios de la población, se convierten en condicionantes materiales de la desintegración social, cuya amenaza será mayor según sea el peso cuantitativo en la estructura social de los sectores excluidos por razones económico-sociales, culturales o políticas.

En otras palabras, una sociedad que excluye materialmente a amplios grupos sociales corre el riesgo de desintegrarse. Esto lo vislumbraron los teóricos más influyentes del pensamiento sociológico; también lo vislumbraron los reformadores sociales de los siglos XIX y XX que, sin ser especialistas en las ciencias sociales, fueron conscientes de que ese riesgo sólo podía evitarse

4. Cfr. L. A. González, La democracia y sus exigencias. San Salvador, ISD, 2009. 
implementando medidas que paliaran o incluso anularan el efecto de las dinámicas de exclusión socioeconómica, cultural y política, por lo menos en lo que atañía a sectores significativos de la población. El pensamiento social de la Iglesia se hace cargo de esa problemática -de la mano de León XIII y su Encíclica Rerum Novarum - que va a ser caracterizada como "la cuestión social" y que tiene que ver con la urgencia de impulsar reformas que ataquen los graves males sociales generados por el capitalismo del siglo XIX.

En este marco, es claro que la integración social tiene un componente material que no puede dejarse de lado: los miembros de la sociedad deben encontrar en ella las condiciones básicas para vivir dignamente. Visto del lado de la desintegración, ese componente material se expresa en la vigencia de mecanismos de exclusión que impiden a una parte significativa de sus miembros tener una vida digna. En este sentido, una sociedad con exclusiones generalizadas y sistemáticas en los planos socioeconómico, cultural y/o político es una sociedad estructuralmente desintegrada. Ahora bien, una cosa es esa desintegración estructural y otra la erosión del sentido de pertenencia social y, junto con ello, la erosión de los vínculos simbólicos (jurídicos, éticos, religiosos, políticos) que unen tanto a individuos como a grupos específicos con un todo social mayor, llámesele patria, nación o país.

Yesto último remite a otro campo problemático: el que se refiere a situaciones en las que se tiene una crisis abierta en la integración social. Porque, ciertamente, para que una situación de crisis de esa naturaleza se dé no basta con que materialmente la sociedad esté desintegrada; el complemento imprescindible para ello es que los miembros de la sociedad que padecen exclusiones materiales -en rigor, sectores significativos de la misma- asuman personalmente (en los afectos y emociones, en sus creencias e ideas) esa exclusión y no vean otra salida más que ponerse al margen del orden (legal, político, ético) establecido. En la sociología clásica, situaciones como éstas fueron calificadas como anómicas; lo propio de ellas es la percepción, por parte del individuo, de la "ausencia de reglas o normas por las cuales regir su conducta" 5 . Y ello, en situaciones extremas, se puede traducir en la pérdida (o erosión) del sentido de pertenencia por parte de actores significativos de la sociedad.

Dicho de otro modo, la integración social se ve socavada no sólo cuando se generan exclusiones materiales intolerables, sino cuando se erosiona el sentido de pertenencia del individuo a la sociedad. Y es que, en síntesis, una sociedad puede tener graves problemas de integración en razón de las exclusiones que genera su modelo socio-económico o su modelo político, sin que esos problemas se traduzcan en una abierta fractura social, en la cual haya sectores sociales significativos -no sólo en cantidad, sino en calidad- que desafíen, desde fuera

5. Del Acebo Ibáñez, E., Brie, R.J., Diccionario de sociología. Buenos Aires, Claridad, 2006, p. 30. 
de la normatividad vigente, el orden social establecido.

Desde la sociología se planteó una primera aproximación al problema que se acaba de describir; sin embargo, faltaba mayor fineza en el análisis para captar los matices del mismo. Para eso se requería una aproximación al tema de la integración no desde el lado de la realidad social -que es lo propio de la sociología - sino del lado del imaginario de los actores, de su subjetividad, de los valores y creencias que la nutren, y que moldean sus opciones y comportamiento individual y colectivo. La antropología cultural llegó en auxilio de la sociología que, por su parte, incorporó a su acervo conceptual nociones antropológicas esenciales que le permitieron entender de mejor manera el problema de la integración social.

Visto desde la antropología -y desde los aportes que ésta ha hecho a la sociología de la cultura-, la integración social es también, si se parte de los sujetos, integración cultural. $Y$ es que para que haya integración social los miembros de la sociedad deben sentirse integrados a ella. A esto se le llama sentido de pertenencia, el cual se nutre de símbolos, tradiciones, costumbres, hábitos y modos de ser que dan vida a la cultura en una sociedad concreta.

Es decir, el sentido de pertenencia -a una patria, a una nación, a un país o a una comunidad - hace parte de la identidad, la cual se fragua a partir de referentes simbólico-culturales que son los que integran al individuo a la sociedad. Dicho de manera más técnica, "la integración supone el funcionamiento más o menos armónico y equilibrado de las distintas partes de una estructura sociocultural, se trata de la sociedad global o de un grupo cualquiera. Dicha integración viene dada primordialmente por el hecho de compartir un marco de referencia normativo-axiológico que prescribe, al menos globalmente, las acciones sociales" 6 . Y es precisamente ese marco de referencia normativo-axiológico el que alimenta el sentido de pertenencia de los miembros de una sociedad. Desde una perspectiva opuesta, cuando ese sentido de pertenencia se erosiona -en virtud de un deterioro de los referentes de identidad (simbólico-culturales), se está a las puertas de un proceso de desintegración social que tendría a la base graves fallas en la integración cultural.

Así pues, la integración social, para lograrse, requiere de una integración material pero también de una integración cultural. Si se vulnera la vida material de los miembros de la sociedad -por pobreza y exclusiones: por injusticias reales- la amenaza de desintegración social aparece en el horizonte, pero esa amenaza sólo cristaliza cuando a esa vulnerabilidad material se añade la erosión del sentido de pertenencia, que es el que permite la integración cultural de la sociedad. Uno de los síntomas más evidentes de la desintegración 
de una sociedad es precisamente la violencia, que a su vez se convierte, cuando se generaliza y escapa al control legal-institucional, en un factor generador de desintegración social.

\section{El problema de la violencia}

Existe, pues, una conexión estrecha entre violencia e integración social. Porque, como ya se apuntó, la violencia además de síntoma de la desintegración social, suele convertirse, una vez que se desata, en factor causal de esta última. Pero la violencia en sí misma es algo difícil de entender no sólo en el plano conceptual, sino en sus manifestaciones, que son ciertamente diversas. Es ciertamente un fenómeno social cuyas expresiones son variadas, pero todas ella involucran un componente de fuerza física, efectiva o potencial, que es ejercido por unos individuos o grupos en contra de otros. Buena parte de los autores -sociólogos, psicólogos sociales, economistas- coinciden en que la violencia puede ser de carácter instrumental (ejercer violencia para obtener algo a cambio) o de carácter expresivo (es decir, ejercer violencia para afirmar o mostrar públicamente un simbolismo determinado, que en muchos casos no es ajeno al trastorno psicológico) $)^{7}$.

No hay acuerdo acerca de la causa (o las causas) de la violencia. Y es que a medida que se han investigado distintas situaciones de violencia (terrorista, política, criminal, familiar, juvenil, etc.) lo que se detecta son factores posibilitadores de la violencia (más que factores causales) que en su conjugación dan pie a las condiciones socio-culturales en las que las prácticas violentas cobran vida. No son la pobreza, el abandono, la marginación, la debilidad de las instituciones, la frustración individual y colectiva, o la erosión de la cultura cívica los factores que generan, por separado, condiciones para la violencia, pero ahí donde aparecen juntos no es improbable que las prácticas violentas aparezcan en escena.

En El Salvador de la postguerra, esos factores se dieron juntos, dando lugar una grave situación de violencia social que hoy por hoy marca profundamente las relaciones individuales y colectivas. Diferentes estudios dan cuenta de esto, siendo pionera en la materia la Universidad Centroamericana "José Simón Cañas" (UCA), que abrió el debate con la publicación de los resultados de una investigación sistemática sobre la violencia en El Salvador (octubre de 1997) ${ }^{8}$. A partir de entonces, otros estudios se han realizado en la misma dirección, tanto en la misma UCA como en otras instituciones y centros de investigación del país. A estas alturas, hay una serie de conocimientos adquiridos sobre el problema de la violencia, los cuales son un punto de partida ineludible para avanzar más

7. Cfr. L. A. González, C. E. Villacorta, “Aproximación teórica a la violencia”. En http://www.uca.edu.sv/ publica/eca/599art4.html.

8. Estudios Centroamericanos (ECA), La cultura de la violencia en El Salvador. ECA, 588, octubre de 1997. 
en su comprensión y para diseñar mecanismos de solución. A continuación se expone, en líneas gruesas, el problema de la violencia en El Salvador.

(a) La violencia que irrumpe en la década de los años 90 en El Salvador es una violencia social ${ }^{9}$, es decir, una violencia que, por un lado, atraviesa al conjunto del tejido social, en todos sus niveles y sectores; y, por otro, es una violencia que afecta cotidianamente a todos los habitantes del país, aunque en grado diverso. Las expresiones más llamativas de esta violencia social son la violencia de los conductores, la actividad criminal de las pandillas (maras) y el crimen organizado, la delincuencia común, los secuestros, las extorsiones y las violaciones. Pero hay manifestaciones más ocultas (o relativamente más ocultas) de esa violencia: la violencia intrafamiliar, la violencia en las escuelas y la violencia en los centros de trabajo.

(b) Los niveles de violencia en El Salvador son tales que lo han convertido en uno de los más violentos de América Latina. Al comienzo del nuevo siglo, los datos de homicidios eran preocupantes: en 1999, 2,270 personas asesinadas; en 2000, 2,341 ${ }^{10}$; en 2001, 2,374; en 2002; 2,346; en 2003, 2,388; y en 2004, 2,933. En la segunda mitad de la primera década del 2000 , la situación es mucho más preocupante, tal como lo revelan los registros del Instituto de Medicina Legal: para 2005 , se tuvieron 3,812 homicidios (con una tasa de 55.5 homicidios por cada 100 mil habitantes); en 2006, 3,928 (55.2 por cada 100 mil habitantes); en 2007, 3,497 (60.9 por cada 100 mil habitantes): en 2008, 3,179 (55.3 por cada 100 mil habitantes) ${ }^{11}$; y, finalmente, en 2009 , 4, 382 (71.9 por cada 100 mil habitantes ${ }^{12}$. Estos datos se reflejan en el gráfico siguiente, en el cual además de recogen las cifras de homicidios para 2001-2008 desagregadas por sexo. Comparados estos datos con cifras de los años noventa, se nota una disminución de los homicidios, pero la misma no permite hacerse ilusiones acerca de los logros obtenidos una década después: en 1994 se registraron 7,673 homicidios intencionales, mientras que en 1995 se registraron $7,877^{13}$.

9. Cfr. L. A. González, "El Salvador en la postguerra: de la violencia armada a la violencia social”. Realidad, 59, septiembre-octubre de 1997, pp. 441-458.

10. Cfr., PNUD, Armas de fuego y violencia. San Salvador, 2003, p. 173.

11. F. M. Vaquerano, Epidemiología de los homicidios en El Salvador periodo 2001-2008. San Salvador, Instituto de Medicina Legal “Dr. Alberto Masferrer”. Unidad de Estadísticas Forenses, 2009, p.14

12. Datos del Instituto de Medicina Legal, a ser publicados próximamente en un informe que aun está en preparación.

13. Cfr. J.M. Cruz, L.A. González, L.E. Romano, E. Sisti, La violencia en El Salvador en los años noventa. Magnitud, costos y factores posibilitadores. Washington, Banco Interamericano de Desarrollo, 1998. J.M. Cruz, L.A. González, L.E. Romano, E. Sisti, "De la guerra al delito: evolución de la violencia en El Salvador". En J.L. Londoño, A. Gaviria, R. Guerrero (Eds.), Asalto al desarrollo. Violencia en América Latina. Washington, Banco Interamericano de Desarrollo, 2000, pp. 172-204. 
GRAFICO 1: NÚMERO Y TASA DE HOMICIDIOS EN EL SALVADOR SEGÚN RECONOCIMIENTOS DE MEDICOS(AS) FORENSES Y SEGÚN BASE CONJUNTA DESDE EL AÑO 2005, EL SALVADOR (2001-2008)

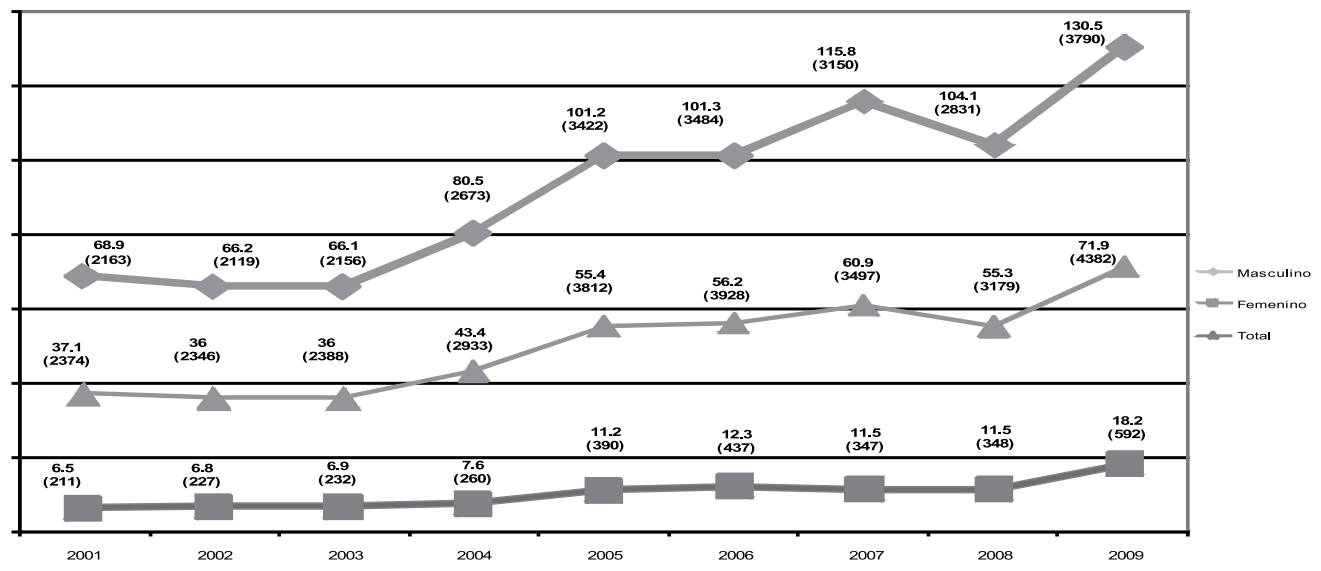

Fuente: Unidad de Estadísticas Forenses. Instituto de Medina Legal

Los datos para el 2009 se recogen en la tabla siguiente, en la cual se presenta, además de la desagregación por sexo, la desagregación por edades. Es impresionante ver cómo los homicidios se concentran en el tramo de edad que va de los 15 a los 34 años, pero golpeando más los hombres jóvenes.

\begin{tabular}{|c|c|c|c|c|c|c|}
\hline GRUPOS DE EDAD & \multicolumn{2}{|c|}{ SEXO MASCULINO } & \multicolumn{2}{c|}{ SEXO FEMENINO } & \multicolumn{2}{c|}{ TOTALES } \\
\hline (AÑOS) & NUMERO & TASA & NUMERO & TASA & NUMERO & TASA \\
\hline$<1$ & 2 & 3.2 & 2 & 3.3 & 4 & 3.3 \\
\hline $1-4$ & 4 & 1.6 & 2 & 0.8 & 6 & 1.2 \\
\hline $5-9$ & 1 & 0.3 & 6 & 1.9 & 7 & 1.1 \\
\hline $10-14$ & 71 & 18.8 & 28 & 7.7 & 99 & 13.3 \\
\hline $15-19$ & 660 & 192.2 & 127 & 36.9 & 787 & 114.5 \\
\hline $20-24$ & 804 & 308.9 & 108 & 36.9 & 912 & 164.8 \\
\hline $25-29$ & 724 & 355.8 & 80 & 31.5 & 804 & 175.6 \\
\hline $30-34$ & 543 & 300.8 & 66 & 28.4 & 609 & 147.4 \\
\hline $35-39$ & 331 & 197.4 & 50 & 23.2 & 381 & 99.5 \\
\hline $40-44$ & 189 & 129.5 & 38 & 20.2 & 227 & 68.0 \\
\hline $45-49$ & 145 & 117.3 & 24 & 15.0 & 169 & 59.5 \\
\hline $50-54$ & 94 & 88.9 & 17 & 12.6 & 111 & 46.1 \\
\hline $55-59$ & 71 & 77.7 & 15 & 13.0 & 86 & 41.6 \\
\hline $60-64$ & 46 & 59.9 & 8 & 8.3 & 54 & 31.1 \\
\hline 65 A + & 77 & 40.5 & 10 & 4.1 & 87 & 20.1 \\
\hline IGNORADO & 28 & & 11 & & 39 & \\
\hline TOTAL & 3790 & 130.5 & 592 & 18.2 & 4382 & 71.9 \\
\hline
\end{tabular}

Fuente: Unidad de Estadísticas Forenses. Instituto de Medicina Legal 
Por su parte, es importante caer en la cuenta de cuánto del total de homicidios es judicializado. La Tabla 2 recoge, además de datos sobre homicidios, datos sobre extorsiones y secuestros (en lo que se refiere únicamente a los casos judicializados en los Juzgados Especializados de Instrucción) ${ }^{14}$. Sólo para los homicidios (simples y agravados), la incidencia se eleva drásticamente en 2008 y 2009, respecto de 2007: para este último año la incidencia de ambos tipos de homicidio suma 753 (para un total de 3,497), mientras que para 2008 suma 2,857 (para un total de 3,179 ) y para 20093,717 (para un total de 4,382 ).

\section{TABLA 2. INCIDENCIA DE CAUSAS PENALES DE LOS DELITOS DE REALIZACIÓN COMPLEJA EN LOS JUZGADOS ESPECIALIZADOS DE INSTRUCCIÓN (2007-2009).}

\begin{tabular}{|c|c|c|c|c|c|c|c|c|}
\hline \multirow{2}{*}{$\begin{array}{c}\text { DELITOS - JUZGADOS } \\
\text { ESPECIALIZADOS DE } \\
\text { INSTRUCCIÓN }\end{array}$} & \multicolumn{2}{|c|}{2007} & \multicolumn{2}{c|}{2008} & \multicolumn{2}{c|}{2009} & \multicolumn{2}{c|}{ TOTAL } \\
\cline { 2 - 10 } & Incidencia & Tasa* & Incidencia & Tasa* & Incidencia & Tasa* & Incidencia & Tasa* \\
\hline HOMICIDIO SIMPLE & 347 & 6.0 & 1,178 & 20.5 & 1,137 & 19.8 & 2,662 & 46.3 \\
\hline HOMICIDIO AGRAVADO & 406 & 7.1 & 1,679 & 29.2 & 2,580 & 44.9 & 4,665 & 81.2 \\
\hline EXTORSION & 1,106 & 19.3 & 1,823 & 31.7 & 2,266 & 39.4 & 5,195 & 90.4 \\
\hline SECUESTRO & 57 & 1.0 & 125 & 2.2 & 143 & 2.5 & 325 & 5.7 \\
\hline TOTAL & 1,916 & 33.4 & 4,805 & 83.7 & 6,126 & 106.6 & 12,847 & 223.7 \\
\hline
\end{tabular}

* Tasa por cada 100,000 habitantes

Fuente Unidad de Información y Estadística. Dirección de Planificación Institucional del Órgano Judicial.

Costó que esa grave situación de violencia fuera reconocida en los años noventa; los gobiernos de ARENA tardíamente aceptaron esa realidad, pero dicho reconocimiento no llevó a impulsar una estrategia integral de seguridad ciudadana ${ }^{15}$. La empresa privada también venció sus resistencias y terminó por reconocer la gravedad de la situación, sobre todo porque, a medida que el crimen organizado se fue afianzando, los golpes criminales contra el sector empresarial se hicieron más directos. Sin embargo, esa toma de conciencia fue tardía, lo cual impidió diseñar, a tiempo, una estrategia integral de seguridad ciudadana. Los sectores empresariales presionaron a los gobiernos de ARENA para que combatieran a las bandas de secuestradores; pero esa presión no fue

14. Los Juzgados Especializados de Instrucción ven delitos en el marco de la Ley contra el crimen organizado. A estos datos hay que sumar los casos vistos por los tribunales ordinarios. Así, para 2008, en los Juzgados de Paz, la incidencia de homicidios simples fue 717 y la de agravados 985 (con un registro del $70 \%$ de los datos); mientras que en 2009 fue de 815 y 1231 (con un registro del 14.3\% de los datos), respectivamente. Cfr. "Incidencia de causas penales varias registradas en los juzgados de Paz durante los años 2008 y 2009 ”. Unidad de Información y Estadística. Dirección de Planificación Institucional del Órgano Judicial, 2010.

15. En 1997, cuando la UCA hizo públicos los resultados de su investigación sobre magnitud y costos de la violencia, el gobierno del entonces presidente Armando Calderón Sol se mostró reticente a aceptar las tesis y conclusiones del estudio, al grado de intentar vetar su divulgación. 
ejercida con la misma determinación en el caso de los otros tipos de violencia. Lo que se impuso fue una estrategia de seguridad ciudadana de carácter punitivo que, al mismo tiempo, fue maliciosamente impulsada con fines electorales que distorsionaron lo que de positivo pudo haber tenido.

(c) La convivencia social en El Salvador está siendo fuertemente socavada por el crimen, la violencia y la impunidad. Hasta ahora, las señales que aparecen en el horizonte son apenas incipientes, pues aún se continúa en el camino trazado por ARENA en materia de seguridad pública. De seguir en la misma dinámica, el tejido social del país experimentará un mayor deterioro, del cual sólo podrá salir con un cambio drástico en los usos y las costumbres de quienes, al amparo de unas instituciones poco sólidas, han hecho de la fuerza, la prepotencia y el abuso una forma de vida. Por el momento, la impunidad es el mejor resguardo a favor del crimen y la violencia, La contracara de esa impunidad-su ambiente propicio- es, por un lado, la liviandad de los mecanismos de coerción estatales, su debilitamiento y laxitud. Y, por otro, el poco (o nulo) arraigo de una cultura cívica, en la que se reivindique el respeto no sólo a las leyes, sino a la dignidad de los demás. Se trata de las caras de todo orden social: coerción y consenso, que no pueden existir la una sin la otra y que, cuando faltan o son extremadamente débiles, conducen a una guerra de todos contra todos y a una situación de "sálvese quien pueda"16.

(d) La portación y tenencia de armas de fuego es uno de los factores que más incide en el alto número de homicidios. Así, del total de homicidios, en el área metropolitana de San Salvador, ocurridos en 1998, el 60 por ciento fue causado con arma de fuego. A nivel nacional, el número de homicidios cometidos con arma de fuego no ha dejado de aumentar: en 1999, 1,598 personas fueron asesinadas con arma de fuego; en 2000, 1,648 ${ }^{17}$; en 2001, 1,682; en 2002, 1,647; en 2003, 1,697; en 2004, 2,262; en 2005, en 2,994; en 2006, 3,112; en 2007, 2,804; y en 2008, 2,482. Si, en la primera década del 2000, se comparan los homicidios cometidos arma de fuego con el total de homicidios por año, se impone la conclusión de que en esa década la mitad de homicidios (o más) se cometieron con arma de fuego. Los datos son contundentes: no hay razones para pensar que vaya disminuir, en el futuro, el impacto de las armas de fuego como factor de muerte, a menos que se ponga en práctica una estrategia efectiva de control de armas que lleve al desarme a la sociedad ${ }^{18}$.

(e) La violencia trae consigo costos económicos significativos, que gravan las posibilidades de desarrollo del país. Por un lado, están los gastos familiares en seguridad -vigilancia, portones, muros, alarmas-; en segundo lugar, los gastos relacionados directamente con pagos de secuestros, extorsiones o recuperación

16. Cfr. L. A. González, “El vacío del autoritarismo”. Contrapunto, 25 de septiembre de 2010.

17. Cfr., PNUD, Armas de fuego y violencia..., p. 173.

18. Cfr., J. M. Cruz, M. A. Beltrán. Las armas de fuego en El Salvador. Situación e impacto sobre la violencia. San Salvador, IUDOP, 2000. 
médica de las víctimas de la violencia; en tercer lugar, lo que gasta el Estado en la policía, los tribunales y el sistema de salud. A medida que la violencia aumenta, esos gastos también crecen, con lo cual la economía nacional se ve seriamente perjudicada. En 1997, los costos personales por lesiones fueron de un poco más de 27 mil dólares. Mientras que, en el mismo año, los gastos legales e institucionales ascendieron a algo más de 284 mil dólares ${ }^{19}$.

Una deuda pendiente en la investigación social es un estudio sistemático de costos de la violencia para la primera década del 2000, semejante al que auspició el Banco Interamericano de Desarrollo (BID) para los años noventa. De todos modos, aun sin contar con un estudio de esa naturaleza, hay datos firmes -como los recogidos en la Tabla 3- que muestran los gastos en administración y seguridad pública, los cuales no sólo representan una cantidad elevada en millones de dólares, sino que no han dejado de crecer en la segunda mitad de la década de 2010. De hecho, entre 2005 y 2009 esos gastos pasaron de 387.6 millones de dólares a 550.1 millones de dólares, en tanto que para el Presupuesto votado para 2010 esa cifra se elevó a 564.7 millones de dólares, pasando en el Presupuesto proyectado para 2011 a 622.6 millones dólares.

\begin{tabular}{|c|c|c|c|c|c|c|c|}
\hline \multicolumn{8}{|c|}{$\begin{array}{l}\text { Tabla 3: Gasto en Administración de Justicia y Seguridad } \\
\qquad(2005-2011)\end{array}$} \\
\hline \multicolumn{8}{|c|}{ (En US\$ millones) } \\
\hline Concepto & 2005 & 2006 & 2007 & 2008 & 2009 & V. 2010 & P. 2011 \\
\hline $\begin{array}{l}\text { Consejo Nacional de la } \\
\text { Judicatura }\end{array}$ & 3.9 & 4.0 & 4.4 & 4.4 & 5.0 & 5.4 & 5.4 \\
\hline Órgano Judicial & 133.6 & 155.2 & 166.3 & 178.5 & 177.4 & 193.2 & 223.1 \\
\hline $\begin{array}{l}\text { Fiscalía General de la } \\
\text { República }\end{array}$ & 19.6 & 21.4 & 29.1 & 37.7 & 41.3 & 34.4 & 33.9 \\
\hline $\begin{array}{l}\text { Procuraduría General de la } \\
\text { República }\end{array}$ & 16.8 & 16.4 & 18.3 & 17.9 & 19.5 & 18.1 & 18.2 \\
\hline $\begin{array}{l}\text { Procuraduría para la } \\
\text { Defensa de los Derechos } \\
\text { Humanos }\end{array}$ & 3.9 & 4.3 & 4.2 & 5.6 & 6.3 & 6.5 & 6.8 \\
\hline Ramo de Gobernación 1/ & 209.3 & 221.5 & 42.2 & 14.1 & 15.0 & 15.9 & 15.5 \\
\hline $\begin{array}{l}\text { Ramo de Seguridad Pública } \\
\text { y Justicia }\end{array}$ & - & - & 205.2 & 313.9 & 281.6 & 290.3 & 315.7 \\
\hline $\begin{array}{l}\text { Transferencias Generales } \\
\text { del Estado }\end{array}$ & 0.5 & 4.0 & 4.0 & 4.0 & 4.0 & 1.0 & 4.0 \\
\hline Total & 387.6 & 426.8 & 473.7 & 576.1 & 550.1 & 564.7 & 622.6 \\
\hline Como \% del PIB & $2.3 \%$ & $2.3 \%$ & $2.3 \%$ & $2.6 \%$ & $2.6 \%$ & $2.6 \%$ & $2.7 \%$ \\
\hline
\end{tabular}

19. Cfr., L. E. Romano, “Los costos de la violencia en El Salvador”. ECA, 588, octubre de 1997, pp. 967-976. 
Fuente: Elaboración propia con base en Mensajes del Proyecto de Presupuesto 2010 y 2011, Informe de Gestión Financiera 2009 y Análisis del Gasto por Áreas de Gestión 2010.

1/ Para los años 2005 y 2006 incluye los gastos de justicia y seguridad pública

Los datos de los años 2010 y 2011 corresponden a los presupuestos votado y proyectado, respectivamente.

A esos gastos se les tiene que sumar los de salud. Para hacerse una idea más cabal de lo que cuesta la violencia en estos momentos, en 2009 los gastos en salud asociados a la misma ascendieron a unos 38 millones de dólares. Según Jaime López, al cierre de 2009, "la violencia que agobia al país no sólo ha ocasionado más de cuatro mil homicidios y mucho pesar en las familias salvadoreñas, sino grandes secuelas en las víctimas de lesiones. Además de los costos humanos, esta escalada le origina al Estado un gasto anual que asciende a 38 millones de dólares sólo por atención médica, según el Ministerio de Salud Pública. De acuerdo con la fuente, el costo promedio de atención en un hospital a un paciente de este tipo es de $\$ 662$ dólares, aunque muchas personas son sometidas a operaciones que pueden costar más de 25 mil ó 40 mil dólares. Según la jefa de la Unidad de Lesiones de Causa Externa (ULCE), del Ministerio de Salud Pública, Silvia Morán, la red hospitalaria atendió a 1,768 lesionados por arma de fuego y 2,115 por arma blanca, de enero al 15 de diciembre"20.

El gráfico siguiente -Gráfico 2- ilustra con claridad estos gastos y el porcentaje del PIB que los mismos representan ${ }^{21}$.

\section{GRAFICO 2: GASTO EN ADMINISTRACIÓN DE JUSTICIA Y SEGURIDAD (2005-2011). (EN US\$ MILLONES)}

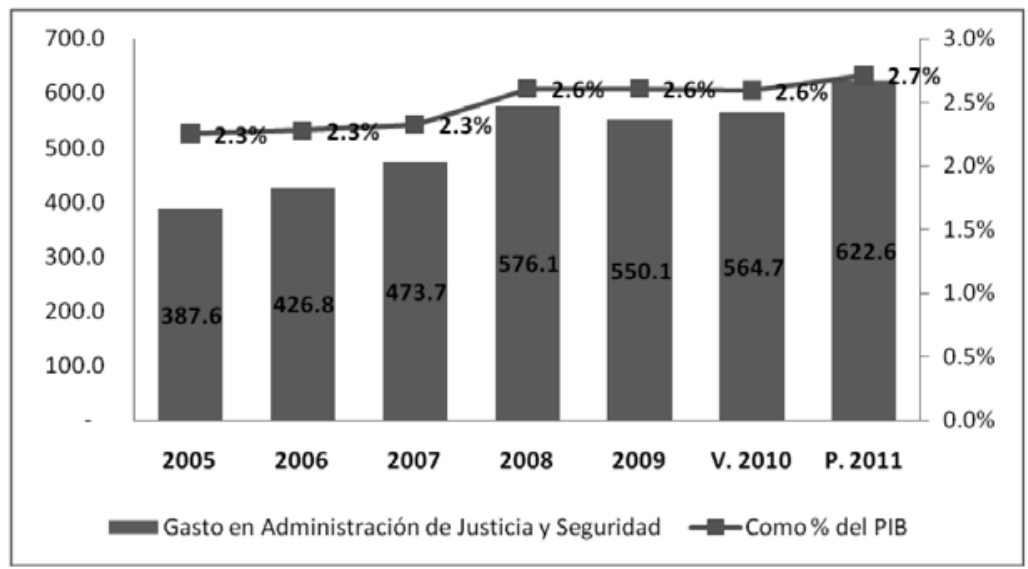

20. J. López, “Violencia cuesta $\$ 38$ millones en atención médica". http://www.elsalvador.com/mwedh/nota/ nota_completa.asp?idCat=6358\&idArt $=4379518$.

21. El autor agradece a Rommel Rodríguez, investigador de la FUNDE, por haberle facilitado los datos de la Tabla 3 y del Gráfico 2. 
(f) La violencia en El Salvador tiene muchas facetas. Una de las más preocupantes es el crimen organizado, quizás el más difícil de combatir, por los nexos políticos, económicos y policiales que ha desarrollado, así como por sus ramificaciones en Centroamérica redes de narcotraficantes, ladrones de vehículos y de secuestradores. Con bastante seguridad se puede hablar de una "integración" centroamericana por la vía del crimen, la cual ha avanzado con más rapidez que los esfuerzos de los gobiernos del área por establecer vínculos firmes de cooperación económica, social y política ${ }^{22}$. La articulación del crimen organizado y las maras no sólo ha dado mayor capacidad operativa al crimen organizado, sino que le ha permitido extender sus operaciones a lo largo y ancho del país. El crimen organizado ha dado señales de estarse territorializando, es decir, de estar ocupando determinados territorios, en los cuales ha impuesto su ley ${ }^{23}$.

Es tan aguda la situación que una vez que Mauricio Funes tomó las riendas del Ejecutivo, la misma se convirtió en uno de sus principales desafíos. "El gobierno de Funes tiene desafíos urgentes que enfrentar y para lo cual necesita, principalmente, del respaldo de su partido, pero también del respaldo de otros actores socio-políticos. Uno de esos desafíos es el que plantea la violencia criminal, que no sólo tiene que ver con las pandillas, sino con el crimen organizado cuya operatividad desborda las fronteras salvadoreñas. Una respuesta inmediata a ese desafío ha sido la decisión sacar a la calle a la Fuerza Armada, para que apoye a la Policía Nacional Civil (PNC) en tareas de seguridad pública. Se trata de una decisión controversial, especialmente porque desde el FMLN -en momentos en que gobernaba ARENA- siempre hubo oposición a una medida de esa naturaleza. Sin embargo, las urgencias que plantea la propagación del crimen -su territorialización- hacen comprensible la decisión del presidente Funes, al menos como una salida de corto plazo, que no impide avanzar en el fortalecimiento de las instituciones encargadas de perseguir y erradicar el crimen: la PNC y la Fiscalía General de la República"24.

(g) Durante las administraciones de ARENA, la respuesta gubernamental al problema de la violencia privilegió la dimensión coercitiva (reacción violenta a la violencia), dejando en segundo plano las dimensiones preventiva y correctiva. El nivel reactivo, como la misma expresión lo dice, consiste en la respuesta que se da ante una situación de violencia, que puede ser de impacto individual o grupal. Desde las esferas de gobierno, esta respuesta suele recaer, en primera instancia, en los organismos policiales, que son los responsables directos de velar por la seguridad ciudadana, una vez que ésta ha sido puesta en riesgo.

22. Cfr., L. A. González, “Centroamérica: violencia, integración regional y globalización”. ECA, 595-596, mayojunio de 1998, pp. 433-448.

23. Cfr. L. A. González, "Violencia social y territorialización del crimen”. ECA, No. 695, 2006, pp. 882-885.

24. L. A. González, “Balance socio-político de 2009 y perspectivas para 2010”. CoLatino, 8 de enero de 2010. 
El nivel preventivo trata de crear las condiciones -sociales, económicas, políticas, culturales- que favorezcan un clima de respeto y tolerancia entre los miembros de la sociedad. Prevenir es favorecer el surgimiento de espacios de recreación, culturales y deportivos, que no sólo sirvan de canal de expresión para las energías grupales - sobre todo, de los adolescentes-, sino para que las personas aprendan a compartir sueños y proyectos. Pero no sólo eso. Se trata también, en segundo lugar, de crear ordenamientos sociales y económicos con un mínimo de equidad y justicia, puesto que una de las fuentes de violencia, en sociedades como la salvadoreña, es la desigualdad socioeconómica prevaleciente. $Y$ todo ello, en tercer lugar, debe ser sostenido por un entramado legal e institucional capaz de responder a los complejos desafíos que plantea la seguridad ciudadana, en el momento actual.

En este sentido, los esfuerzos desplegados por los gobiernos de ARENA central, a lo largo de los años noventa y casi toda la década siguiente, para garantizar la seguridad ciudadana - vista como un problema de seguridad pública- no fueron en lo absoluto exitosos como creyeron quienes defienden el enfoque meramente reactivo. El énfasis puesto en esa dimensión, en detrimento de la dimensión preventiva, ha revelado graves deficiencias. Aparte de ello, en los últimos 20 años, las instituciones responsables de la seguridad pública y la justicia no sólo fueron invadidas por el crimen y la corrupción, sino que no pudieron articular su trabajo, dando pie a la incompetencia y al encubrimiento.

Visto en conjunto, en los últimos 20 años, los aportes más relevantes para trabajar por la prevención de la violencia se gestaron en instituciones no gubernamentales, como universidades, centros de investigación u organismos internacionales como el PNUD. Salvo los esfuerzos del Ministerio de Educación 口con proyectos como el Fondo Alegría ${ }^{25}$, las iniciativas de otras instituciones, por ejemplo, la Policía Nacional Civil, tuvieron poca relevancia social y escaso impacto público. Estrategias como la seguida en la Colonia Zacamil, donde se buscó integrar a la comunidad en los esfuerzos de la policía para garantizar la seguridad pública, no se generalizaron. También fue de poco impacto la iniciativa, surgida del seno del Consejo de Seguridad Pública, para crear espacios de recreación en los lugares de mayor violencia social. Estas iniciativas y otras, aunque valiosas, incidieron poco en la reducción de los niveles de violencia.

(h) Por último, en El Salvador persisten esquemas culturales que valoran de manera positiva la fuerza, la agresividad y la prepotencia como estilos ideales de comportamiento. Es decir, hay esquemas culturales autoritarios, heredados del pasado, que favorecen el abuso y la violencia sobre los más débiles. $Y$ esto de un modo bastante generalizado en el conjunto de la sociedad ${ }^{26}$. La cultura

25. Un bono entregado a las escuelas por las autoridades de educación para mantener sus puertas abiertas los fines de semana, con el objetivo de que alumnos y padres de familia puedan hacer uso del espacio escolar para compartir actividades artísticas, culturales o deportivas.

26. ECA, “La cultura de la violencia”. ECA, 588, octubre de 1997, pp. 937-949. 
predominante es caldo de cultivo de prácticas violentas; erradicar esa cultura, fraguando una distinta, en la que los valores humanos fundamentales ocupen un lugar central, es crucial para avanzar hacia una sociedad menos violenta. De lo que se trata es de construir una cultura de la tolerancia, del respeto a la ley, la responsabilidad ciudadana, la participación y el compromiso por la condición de los demás -de los otros y las otras-, especialmente de quienes se encuentran en situaciones de vulnerabilidad extrema. Y es que la superación del problema de la violencia exige un compromiso de la sociedad civil para su erradicación o disminución, lo cual supone un mayor protagonismo para los gobiernos locales en el fortalecimiento de la participación ciudadana, toda vez que el gobierno central no ha sido capaz de enfrentar de manera integral el problema.

\section{Justicia y violencia}

La palabra "justicia", como se indicó en la introducción, apunta en lo fundamental al ámbito normativo, tanto jurídico como moral. Respecto de lo primero cabe decir que la justicia en su implicación jurídica apunta a lo que a cada cual le corresponde según la ley. Es decir, la ley es lo que "ajusta" las relaciones entre individuos y grupos; la ley es la que regula las relaciones sociales; la ley es la que iguala, normativamente, a quienes son en realidad desiguales. $Y$ el peso de la ley deriva, según la tradición iusnaturalista, de su origen natural. En palabras de Montesquieu, “las leyes, en la significación más generalizada, son las relaciones necesarias que derivan de la naturaleza de las cosas" 27.

La justicia legal, en este sentido, radica en hacer que la igualdad jurídica prevalezca por encima de otras desigualdades que, en teoría, deberían disminuir o ser menos hirientes con el imperio de la ley. El republicanismo moderno hizo de este propósito una de sus banderas más importantes, junto con la de controlar, desde una interpretación y aplicación en manos del Poder Judicial, el poder despótico del soberano ${ }^{28}$. Como dice Alexis de Toqueville, "si la fuerza de los tribunales ha sido en todos los tiempos la garantía más grande que se puede ofrecer a la independencia individual, esto es particularmente cierto en los siglos democráticos [cuando] los derechos y los intereses particulares se hallan siempre en peligro, si el poder judicial no crece ni se extiende a medida que las condiciones se igualan"29.

Ahora sabemos que no basta con la justicia legal -ni con los arreglos institucionales de tipo contractualista a la manera de los propuestos por John Rawls en su Teoría de la justicia ${ }^{30}$ - para que la justicia no legal (económica, política, social, cultural) cobre vigencia en una realidad determinada. Amartya Sen ha

27. Montesquieu, El espíritu de las leyes. Barcelona, Edicomunicación, 2003, p. 15.

28. Cfr. L. A. González, La independencia judicial en El Salvador. Un ensayo de interpretación de la historia de la Corte Suprema de Justicia. San Salvador, Dirección de Comunicaciones y Relaciones Públicas, 2009, pp. 9-16.

29. A. de Toqueville, La democracia en América. Cap. VII.

30. J. Rawls, Teoría de la justicia. FCE, 1979. 
contribuido de manera decisiva al debate, a partir de su crítica a la teoría de la justicia de Rawls. Y es que a Amartya Sen le interesa no tanto el asunto de la naturaleza de la justicia perfecta y cómo esta se puede asegurar de una vez y por siempre, sino "la cuestión del mejoramiento de la justicia y la superación de la injusticia", lo cual supone reconocer que "la justicia guarda relación, en última instancia, con la forma en que las personas viven sus vidas y no simplemente con la naturaleza de las instituciones que las rodean... El énfasis en las vidas reales en la evaluación justicia tiene muchas implicaciones de largo alcance para la naturaleza y el alcance de la idea de justicia" ${ }^{31}$.

Partir de la vida de las personas cuando se habla de justicia o de injusticia: este enunciado es parte de una arraigada preocupación moral, propia de prácticamente todas las civilizaciones humanas, sobre todo en sus creaciones religiosas. En efecto, las distintas tradiciones religiosas han hecho de la justicia el bien moral por excelencia. En el caso concreto del cristianismo, obrar con justicia es dar a cada cual lo que le corresponde en virtud de su dignidad humana -una dignidad humana establecida por Dios, al crearnos a su imagen y semejanza-. Lo cual quiere decir que, como todos los humanos somos iguales en dignidad, obrar con justicia es hacer prevalecer esa igualdad fundamental entre los seres humanos. Lo contrario de la justicia es la injusticia: la vigencia de desigualdades que laceran la dignidad humana. De ahí la condena del cristianismo a la injusticia --o mejor dicho a las distintas injusticias que se generan en la sociedad-.

La injusticia económica estuvo en la mira de los primeros cristianos -de hecho, el tema es central en el Antiguo Testamento- y se ha mantenido como tema de preocupación a lo largo de los siglos, siendo uno de los ejes centrales del pensamiento social de la Iglesia. En los años setenta, Monseñor Oscar Romero se refirió a esa injusticia como "violencia estructural", porque la misma forzaba a la mayor parte de salvadoreños y salvadoreñas a vivir en condiciones que violentaban su dignidad humana.

En la visión de Monseñor Romero -en sintonía con el pensamiento social de la Iglesia-la injusticia económica no lo es todo; hay otros tipos de injusticia: institucional-estatal (la que excluye de la participación a los ciudadanos y garantiza, con la fuerza, la injusticia económica), social (que impide a amplios sociales el acceso a la salud, a la vivienda y a la educación) y cultural (la que segrega a amplios grupos sociales del acceso a bienes culturales que los dignifiquen, y que más bien los inserta en una cultura de la muerte, el consumismo, la sumisión y el desarraigo.

Por último, esas injusticias tienen su propia lógica de violencia: violencia institucional-estatal, violencia de exclusión social y violencia de exclusión 
cultural. En determinados contextos -como el de El Salvador de los años setenta - esas violencias (e injusticias) pueden dar lugar una violencia reactiva de carácter revolucionario, cuya legitimación es, en boca de quienes la promueven, terminar con las injusticias prevalecientes.

Pero no siempre es así: muchas veces las injusticias y violencias del orden establecido dan lugar a la violencia sorda de los excluidos, a una violencia que los excluidos ejercen en contra de ellos mismos e instintivamente en contra de quienes se benefician (directa o indirectamente) de las injusticias y violencias vigentes. Esta violencia de los excluidos puede asimilarse -como viene sucediendo en El Salvador desde la década de los años noventa- a otras formas de violencia ejercidas por quienes viven y se lucran de la violencia: delincuencia común y crimen organizado, que generan, a su vez, sus propias injusticias en las víctimas de sus atropellos.

\section{Reflexión final}

En definitiva, en el marco del pensamiento social de la Iglesia, las injusticias económica, social, política y cultural no sólo son violencias en sí mismas, sino que generan diversos tipos de violencia reactiva, las cuales en general -incluso la violencia revolucionaria, más allá de los que digan quienes la protagonizanterminan dando lugar a otras injusticias y más violencia: es lo que Monseñor Romero llamó el "espiral de la violencia". Hay, pues, una relación que va de la injusticia a la violencia, pero que luego se revierte: la violencia genera también injusticia.

En la línea de Amartya Sen, los arreglos institucionales y legales deberían adecuarse a la realidad de injusticia, de modo que esa realidad se vaya modificando paulatinamente volviéndose menos injusta. Este es el camino para avanzar en la erradicación (también paulatina) de la violencia en sus diferentes expresiones. La violencia se supera con justicia, pero no con una justicia ideal (o perfecta), sino con una que parta de la vida real de la gente, de sus necesidades de trabajo, de salud, de educación y de vivienda. $Y$ es que así como las distintas injusticias (y la violencia que las acompaña) desintegran a la sociedad -la erosionan y socavan el nexo social-, las distintas concreciones de la justicia permiten no sólo superar las distintas violencias, sino avanzar hacia sociedades más integradas, estables y solidarias.

De tal suerte que, en El Salvador, no se puede aspirar a tener una sociedad integrada, cuando las situaciones de injusticia marcan la vida cotidiana de sus miembros y cuando la violencia ha penetrado tan profundamente en el tejido social, cultural e institucional. Es decir, la sociedad salvadoreña es una sociedad desintegrada por las injusticias vigentes y la violencia. Está bien que se preste atención a la violencia, pero sin olvidar las injusticias que prevalecen, porque 
después de todo es en la superación de estas últimas donde está la clave para avanzar hacia una convivencia social más solidaria y acorde con la dignidad de sus miembros. Es para esto que debe servir la justicia legal y los arreglos institucionales a los que la misma da lugar.

\section{Bibliografía}

1. L.A. González, Cultura, educación e integración social en El Salvador. Cuaderno de Trabajo No. 1. CENICSH, junio de 2010.

2. L. A. González, La democracia y sus exigencias. San Salvador, ISD, 2009.

3. L. A. González, C. E. Villacorta, “Aproximación teórica a la violencia”. En http://www.uca.edu.sv/publica/eca/599art4.html.

4. L. A. González, "El Salvador en la postguerra: de la violencia armada a la violencia social”. Realidad, 59, septiembre-octubre de 1997.

5. L. A. González, "El vacío del autoritarismo". Contrapunto, 25 de septiembre de 2010.

6. L. A. González, "Centroamérica: violencia, integración regional y globalización”. ECA, 595-596, mayo-junio de 1998.

7. L. A. González, "Violencia social y territorialización del crimen". ECA, No. 695, 2006, pp. 882-885.

8. L. A. González, "Balance socio-político de 2009 y perspectivas para 2010". CoLatino, 8 de enero de 2010.

9. L. A. González, La independencia judicial en El Salvador. Un ensayo de interpretación de la historia de la Corte Suprema de Justicia. San Salvador, Dirección de Comunicaciones y Relaciones Públicas, 2009, pp. 9-16.

10. Del Acebo Ibáñez, E., Brie, R.J., Diccionario de sociología. Buenos Aires, Claridad, 2006.

11. PNUD, Armas de fuego y violencia. San Salvador, 2003.

12. F. M. Vaquerano, Epidemiología de los homicidios en El Salvador periodo 2001-2008. San Salvador, Instituto de Medicina Legal "Dr. Alberto Masferrer". Unidad de Estadísticas Forenses. 
13. J.M. Cruz, L.A. González, L.E. Romano, E. Sisti, La violencia en El Salvador en los años noventa. Magnitud, costos y factores posibilitadores. Washington, Banco Interamericano de Desarrollo, 1998.

14. L. E. Romano, “Los costos de la violencia en El Salvador”. ECA, 588, octubre de 1997.

15. J. Rawls, Teoría de la justicia. FCE, 1979.

16. Amartya Sen, La idea de justicia. México, Taurus, 2010. 